\title{
Diagnosis of biliary tract and ampullary carcinomas
}

\author{
Kazuhiro Tsukada ${ }^{1}$, Tadahiro Takada ${ }^{2}$, Masaru Miyazaki ${ }^{3}$, Shuichi Miyakawa ${ }^{4}$, Masato Nagino ${ }^{5}$, \\ Satoshi Kondo ${ }^{6}$, Juni Furuse ${ }^{7}$, Hiroya SAito ${ }^{8}$, Toshio Tsuyuguchi ${ }^{9}$, Fumio Kimura ${ }^{3}$, Hideyuki Yoshitomi ${ }^{3}$, \\ Satoshi Nozawa ${ }^{3}$, Masahiro Yoshida ${ }^{2}$, Keita Wada ${ }^{2}$, Hodaka Amano ${ }^{2}$, and Fumihiko Miura ${ }^{2}$ \\ ${ }^{1}$ Department of Surgery and Science, Graduate School of Medicine and Pharmaceutical Science for Research, University of Toyama, \\ 2630 Sugitani, Toyama 930-0194, Japan \\ ${ }^{2}$ Department of Surgery, Teikyo University School of Medicine, Tokyo, Japan \\ ${ }^{3}$ Department of General Surgery, Chiba University Graduate School of Medicine, Chiba, Japan \\ ${ }^{4}$ Department of Gastroenterological Surgery, Fujita Health University, Toyoake, Japan \\ ${ }^{5}$ Division of Surgical Oncology, Department of Surgery, Nagoya University Graduate School of Medicine, Nagoya, Japan \\ ${ }^{6}$ Department of Surgical Oncology, Hokkaido University Graduate School of Medicine, Sapporo, Japan \\ ${ }^{7}$ Hepatobiliary and Pancreatic Oncology Division, National Cancer Center Hospital East, Chiba, Japan \\ ${ }^{8}$ Department of Radiology, Asahikawa Kosei General Hospital, Asahikawa, Japan \\ ${ }^{9}$ Department of Medicine and Clinical Oncology, Chiba University Graduate School of Medicine, Chiba, Japan
}

\begin{abstract}
Diagnostic methods for biliary tract carcinoma and the efficacy of these methods are discussed. Neither definite methods for early diagnosis nor specific markers are available in this disease. When this disease is suspected on the basis of clinical symptoms and risk factors, hemato-biochemical examination and abdominal ultrasonography are performed and, where appropriate, enhanced computed tomography (CT) and/or magnetic resonance cholangiopancreatography (MRCP) is carried out. Diagnoses of extrahepatic bile duct cancer and ampullary carcinoma are often made based on the presence of obstructive jaundice. Although rare, abdominal pain and pyrexia, as well as abnormal findings of the hepatobiliary system detected by hemato-biochemical examination, serve as a clue to making a diagnosis of these diseases. On the other hand, the early diagnosis of gallbladder cancer is scarcely possible on the basis of clinical symptoms, so when this cancer is found with the onset of abdominal pain and jaundice, it is already advanced at the time of detection, thus making a cure difficult. When gallbladder cancer is suspected, enhanced CT is carried out. Multidetector computed tomography (MDCT), in particular - one of the methods of enhanced $\mathrm{CT}-$ is useful for decision of surgical criteria, because MDCT shows findings such as localization and extension of the tumor, and the presence or absence of remote metastasis. Procedures such as magnetic resonance imaging, endoscopic ultrasonography, bile duct biopsy, and cholangioscopy should be carried out taking into account indications for these procedures in individual patients. However, direct biliary tract imaging is necessary for making a precise diagnosis of the horizontal extension of bile duct cancer.
\end{abstract}

Key words Biliary tract neoplasm · Endoscopic ultrasonography (EUS) - Multidetector computed tomography (MDCT) · Guidelines

Offprint requests to: $\mathrm{K}$. Tsukada

Received: October 1, 2007 / Accepted: October 22, 2007

\section{Introduction}

Of biliary tract cancers, extrahepatic bile duct cancer and carcinoma of the papilla are often diagnosed with the onset of obstructive jaundice. In only a few cases is a diagnosis of these cancers made prior to the onset of jaundice, based on a detailed examination of symptoms of cholangitis. Also, a diagnosis of biliary tract cancer is occasionally made in a patient without symptoms, on the basis of abnormal results on hemato-biochemical examination of the hepatobiliary system. Although some risk factors for biliary tract cancer have been indicated, neither an algorithm for early diagnosis nor hemato-biochemical examinations, nor clinical symptoms and tumor markers that are specific to this disease are available. As far as gallbladder cancer is concerned, it is already advanced at the time when its diagnosis has been made, based on the presence of abdominal pain and jaundice. The first step in the diagnostic imaging of biliary tract cancer is abdominal ultrasonography; enhanced computed tomography (multidetector CT where available) is carried out for patients with suspected biliary tract tumors. Magnetic resonance imaging (MRI, including magnetic resonance cholangiopancreatography [MRCP]) has come into increased use as an alternative procedure for direct biliary tract imaging, and is indispensable in making a precise diagnosis of horizontal extension. Other excellent diagnostic procedures include endoscopic ultrasonography, bile duct biopsy (cytologic diagnosis), and cholangioscopy. These should be used with care as test procedures prior to treatment while paying attention to the symptoms of individual patients. As guidelines for the diagnosis of gallbladder cancer, this article poses five clinical questions (CQs), in addition to a providing a literature review related to each of these questions. In 
the responses to the CQs, recommendations for treatment are noted (grades of these recommendations are defined in Table $1^{1}$ ). Also, levels of evidence are given (in parentheses) for findings in reference citations (see definitions of levels in Table $2^{1}$ ).

CQ 1 By which clinical symptoms is biliary tract cancer suspected?

When jaundice, right upper abdominal pain, and abnormal findings detected by hemato-biochemical examination of the hepatobiliary system have been observed, examination should be carried out, bearing biliary tract carcinoma in mind (recommendation B).

In $90 \%$ of patients with bile duct cancer, the initial symptom is jaundice ${ }^{2}$ (level VI). Other symptoms, including pruritus, mild upper abdominal pain, and weight loss are found in more than half of the patients with this cancer ${ }^{2-4}$ (level VI). There is a report that, in patients without jaundice, abdominal pain is present in $44 \%$ of these patients, pyrexia in $17 \%$, anorexia in $11 \%$, and general lassitude in $11 \%$ as initial symptoms, but that $27 \%$ of the patients (level IV) have no symptoms. ${ }^{5}$

The clinical symptom observed most frequently in gallbladder cancer is right upper abdominal pain, in $79 \%-89 \%$ of the patients, ${ }^{6-8}$ followed by nausea/vomiting, in $52 \%-53 \%,{ }^{6,7}$ and other signs and symptoms, such as weight loss, jaundice, anorexia, abdominal distention, pruritus, and tarry stools ${ }^{6}$ (level IV). Many of these patients have such complications as cholecystoli-

Table 1. Strength of recommendations ${ }^{1}$

A, Strongly recommend performing the clinical action

$\mathrm{B}$, Recommend performing the clinical action

$\mathrm{C} 1$, The clinical action may be considered although there is a lack of high-level scientific evidence for its use. May be useful

$\mathrm{C} 2$, Clinical action not definitively recommended because of insufficient scientific evidence. Evidence insufficient to support or deny usefulness

$\mathrm{D}$, Recommend not performing the clinical action thiasis and anomalous arrangement of pancreaticobiliary ducts, so it cannot be denied that the above mentioned clinical symptoms have occurred due to these complications. Thus, it may be difficult to conclude that they are specific symptoms induced by gallbladder cancer.

The clinical symptoms frequently encountered in ampullary carcinoma are jaundice, pyrexia, abdominal pain followed by general lassitude, weight loss, anorexia, and back pain. Jaundice is reported to be observed in $72 \%-90 \%$ of these patients ${ }^{9-11}$ (levels IV, VI), but it is characterized by occasional fluctuation ${ }^{11}$ (level VI). There is a report that pyrexia is present in $44 \%{ }^{11}$ (level IV) and abdominal pain occurs in $45 \%$ of patients ${ }^{10}$ (level IV).

CQ 2 What is the first step in the diagnosis of biliary tract cancer?

\section{Noninvasive abdominal ultrasonography and hematological examination can be the first step in diagnosis (recommendation $B$ ).}

\section{Hemato-biochemical examination}

Liver dysfunction is present in patients with bile duct obstruction.(increases in alkaline phosphatase, $\gamma$ glutamyl transpeptidase, and total bilirubin) ${ }^{12,13}$ (level III), but no specific hemato-biochemical examination to diagnose biliary tract carcinoma is available.

\section{Abdominal ultrasonography (abdominal US; see Figs 1-3)}

The diagnostic imaging to be performed in the first place is abdominal US when biliary tract cancer is suspected. Particularly, this procedure facilitates the detection of dilated intrahepatic bile ducts (Fig. 1a), thus enabling assessment of the obstructed site ${ }^{12,13}$ (level III). Fifty percent of gallbladder cancers cases are depicted as tumors on abdominal US (Fig. 3). ${ }^{11}$

The detectability of bile duct cancer varies from $21 \%$ to $90 \%$ (Figs. 1b, 2) $2,5,14,16$ and the detectability of distal

Table 2. Levels of evidence ${ }^{1}$

\begin{tabular}{ll}
\hline Level I & Systematic review/meta-analysis \\
Level II & One or more randomized clinical trials \\
Level III & Nonrandomized controlled trials \\
Level IV & Analytic epidemiology (cohort studies and case-control studies) \\
Level V & Descriptive study (case reports and case-series studies) \\
Level VI & $\begin{array}{l}\text { Opinions of expert panels and individual experts not based on } \\
\text { patient's data }\end{array}$ \\
\hline
\end{tabular}



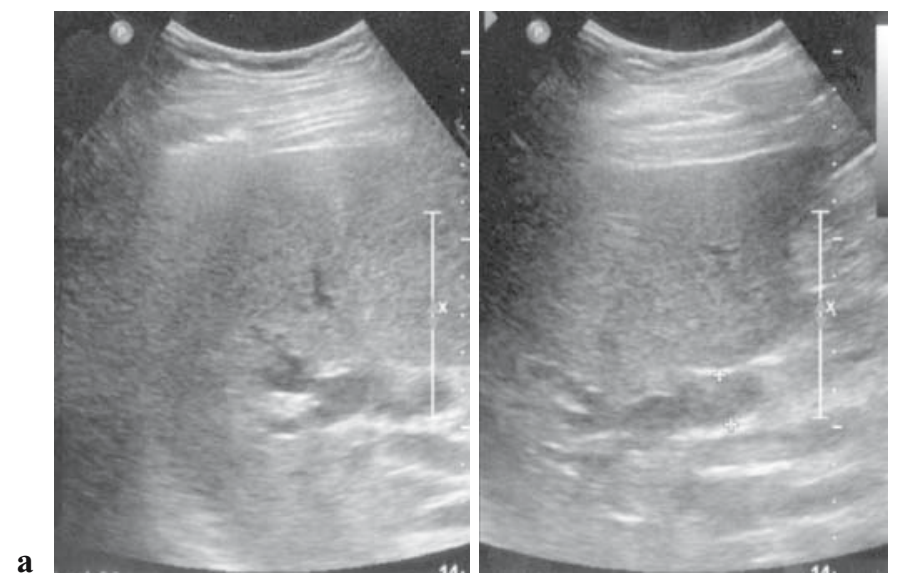

Fig. 1. Extracorporeal ultrasonography (US) images of a case of cancer in the hepatic hilar bile duct, showing dilated right intrahepatic bile duct (a), but imaging of hepatic hilar tumor is poor (indirect findings showing the presence of tumor) (b)

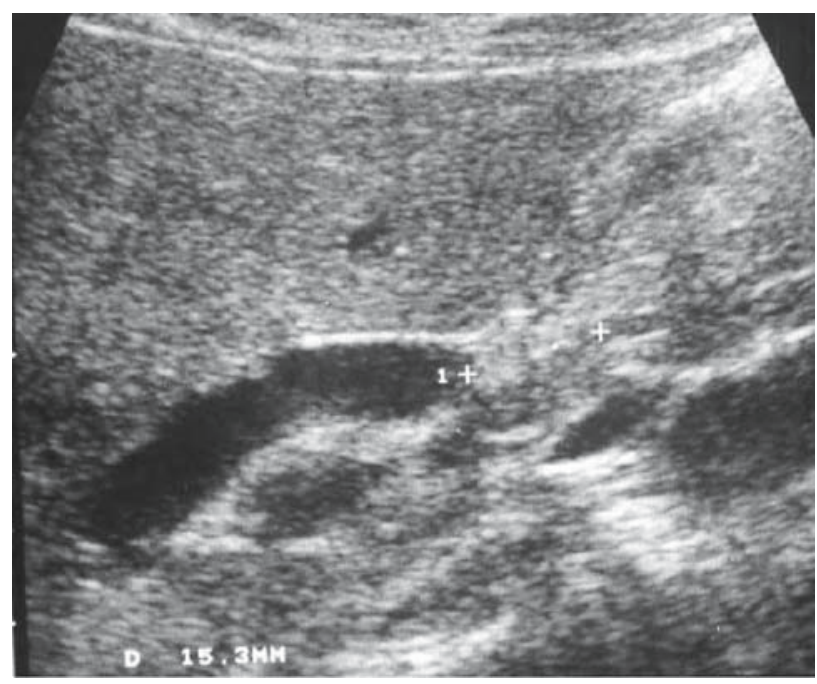

Fig. 2. Extracorporeal US image of a case of middle bile duct cancer, showing blockage of the bile duct due to the tumor in the superior margin of the pancreas head (direct finding of tumor)

bile duct carcinoma is low. When dilatation of the intrahepatic bile duct without extrahepatic bile duct dilatation is observed, stricture of the hilar bile duct is suspected (Fig. 1a,b), but middle and lower bile duct stricture is suspected when both intrahepatic and extrahepatic bile ducts are dilated ${ }^{2,5,14-16}$ (level IV).

\section{Tumor markers}

No tumor markers specific to biliary tract cancer are available. Improved diagnostic ability can be achieved with a combination of tumor markers and other procedures, but early diagnosis using tumor markers alone is difficult $^{12,13,17-24}$ (levels II, III, IV).

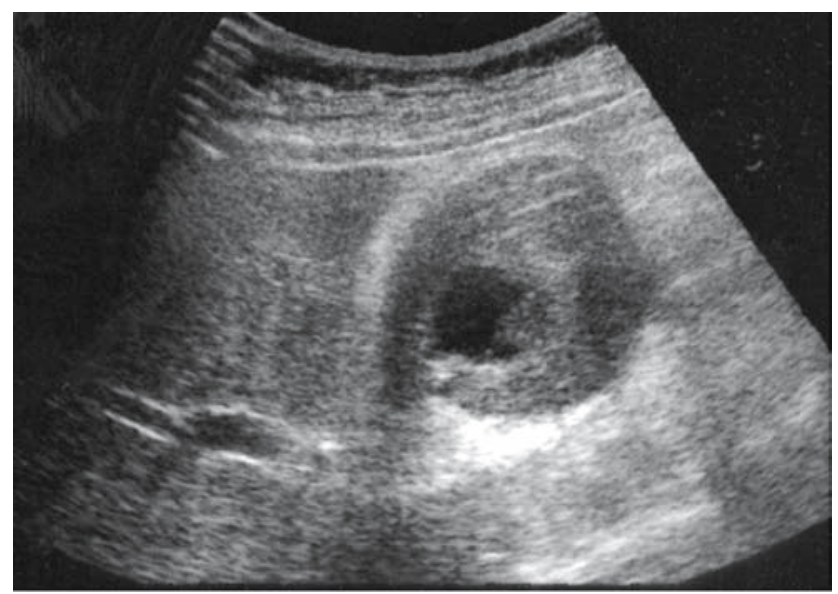

Fig. 3. Extracorporeal US image of an advanced gallbladder cancer (wall-thickness type), showing advanced gallbladder cancer with circumferential wall thickness

Carbohydrate antigen 19-9 (CA19-9) ${ }^{17-21}$ (levels II, III) CA19-9 is not evident to confirm of diagnosis in patients with suspected biliary tract cancer. However:

- It is increased in $50 \%-79 \%$ of patients with biliary tract cancer.

- It also increases in patients with cholestasis.

- It does not increase in patients with biliary tract cancer if sialyl $\mathrm{Le}^{\mathrm{a}}$ is negative.

Carcinoembryonic antigen $(C E A)^{17,21-23}$ (level III)

- CEA is increased in $40 \%-70 \%$ of patients with biliary tract cancer.

- Cholestasis has no impact on CEA.

Cancer antigen 125 (CA125) $)^{21,24}$ (level IV)

- CA125 is increased in 58\% of patients with gallbladder cancer $(17 \mathrm{U} / \mathrm{ml}$ as the cutoff point).

- It tends to increase in patients with ascites.

Although the values of other markers, including DUPAN-2, CA195, CA242, and interleukin (IL)-6 are occasionally measured, their clinical usefulness is not $\operatorname{clear}^{21}$ (level II).

CQ 3 What is the second step in the diagnosis of bile duct cancer?

CT and MRI (including MRCP) are useful for localization of the lesion and assessment of the degree of its extension (recommendation B). Also, direct cholangiography is useful for the diagnosis of the horizontal extension of bile duct cancer (recommendation C1). 


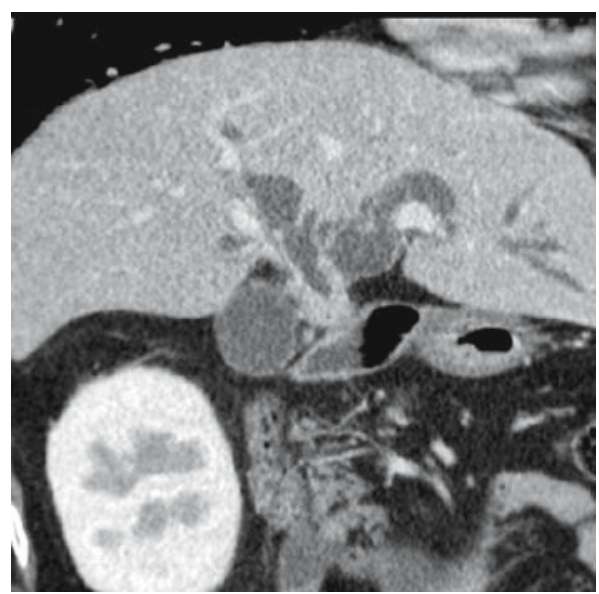

Fig. 4. Multidetector computed tomography (MDCT) image of cancer of the hilar bile duct reconstructed along the left and right confluence of the hepatic duct. It suggests invasion as well as thickening of the hepatic duct as far as the anterior and posterior segment branching

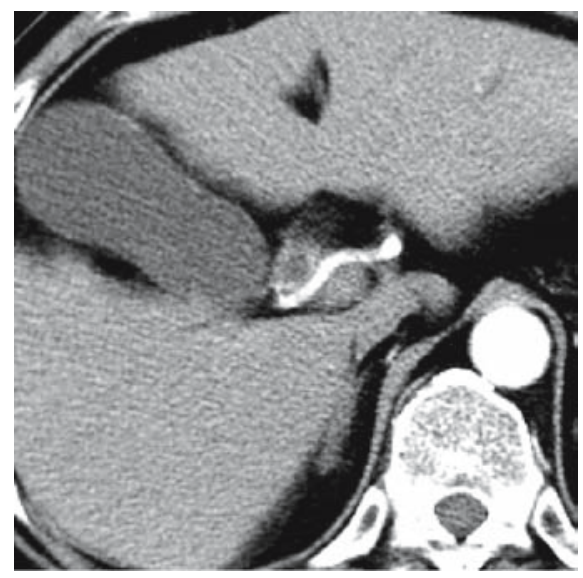

Fig. 5. MDCT intersection image of the same patient as in Fig. 4 (arterial phase) the right hepatic artery is adjacent to the tumor

\section{$C T$}

Enhanced CT (multidetector computed tomography [MDCT] where available) enables the assessment of blood-flow dynamics in the bile duct wall and it is useful for making a diagnosis of the main invasion site (Fig. 4). However, there are cases in which no association of thickening of the bile duct wall is observed, so the use of $\mathrm{CT}$ alone is not sufficient for a diagnosis of the precise degree of extension and depth of mural invasion ${ }^{22,25}$ (levels IV, II). A diagnosis of vascular invasion with the use of enhanced CT (MDCT where available) is of importance for decision-making in diagnostic policies (Figs. 5, 6) $22,25,26$ (levels II-IV).

In Western countries, there are many studies of the diagnosis and treatment of bile duct cancer associated

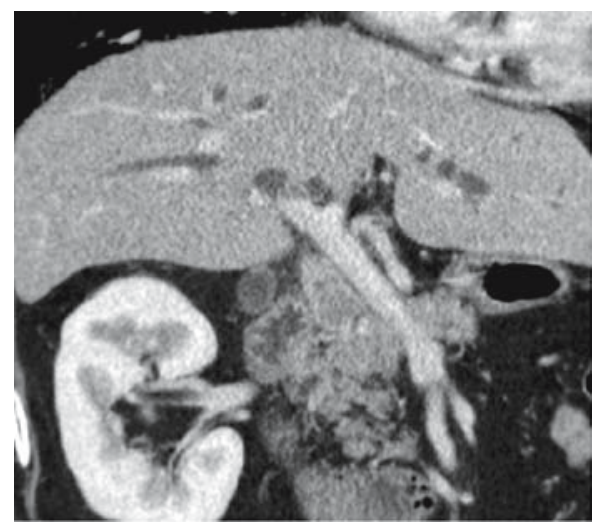

Fig. 6. MDCT intersection image of the same patient as in Fig. 4 (venous phase) reconstructed along the left and right confluence of the hepatic duct. The portal vein runs parallel with the tumor

with primary sclerosing cholangitis (PSC), in which it is demonstrated that, in regard to sensitivity and specificity, three-dimensional CT (3 D-CT) is as useful as cholangiography in assessing this cancer ${ }^{27}$ (level IV). On the other hand, it is also known that the diagnosis of bile duct cancer associated with PSC is difficult. The presence of lymph node enlargement, which is useful for making a diagnosis of cancers, does not mean that there is malignancy, because lymph node enlargement also occurs in inflammatory changes in PSC $^{28}$ level IV). Enhanced CT detect the lymph node swelling, however it is not effective in differentiating whether the swelling indicates an inflammatory or a malignant change $e^{29,30}$ (level IV).

$M R C P$, endoscopic cholangiopancreatography (ERCP), and percutaneous transhepatic cholangiography $(P T C)$ (Fig. 7)

MRCP is useful in identifying the site of bile duct stricture, in diagnosing the extension of invasion, and in confirming the presence or absence of abnormal pancreas and bile duct confluence ${ }^{31}$ (level IV). The sensitivity of MRCP in differentiating between benign and malignant bile duct strictures is $70 \%-96 \%$ and that in identifying the site of obstruction is $94 \%-99 \%$. $^{32-34}$ Therefore, MRCP is a recommendable procedure.

Although direct cholangiography modalities, such as ERCP and cholangiography using percutaneous transhepatic biliary drainage (PTBD), are associated with a risk of incidental disease and are not necessarily required $^{35}$ (level IV), these modalities are useful for the diagnosis of the horizontal extension of nodules or the nodular invasive type of bile duct cancer ${ }^{36,37}$ (level IV) (Fig. 8).

A cytologic diagnosis of bile can be carried out with the use of endoscopic retrograde cholangiography 
(ERC), but the rate of accurate diagnosis using this procedure is approximately $30 \%$. The rate increases by $40 \%-70 \%$ by using brush biopsy ${ }^{22}$ (level II).

\section{Cholangioscopy}

Percutaneous transhepatic cholangioscopy (PTCS) enables the detailed examination and direct-vision biopsy of the lumen of the bile duct. PTCS is useful in

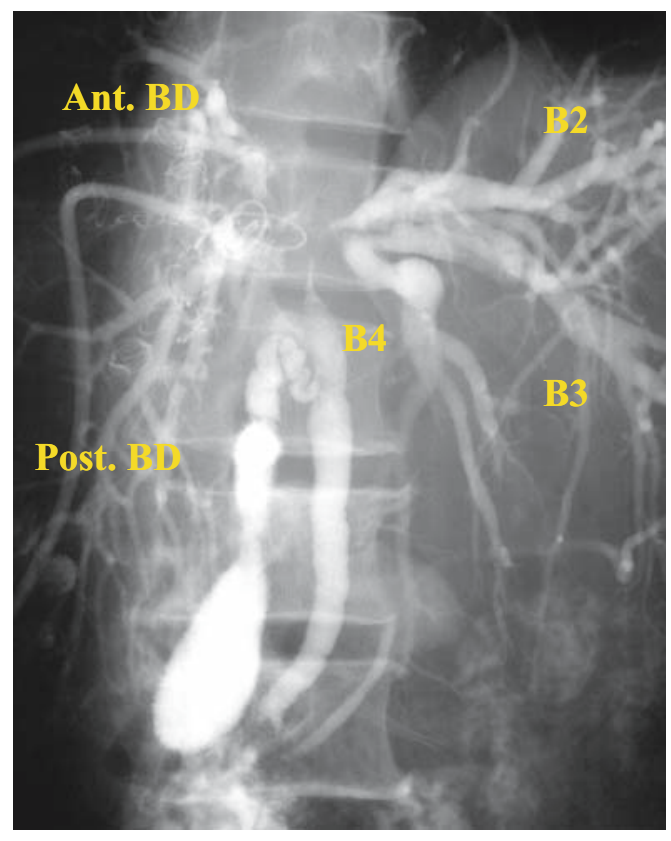

Fig. 7. Percutaneous transhepatic cholangiography of cancer of the hilar bile duct $(B D)$ : the stricture has extended as far as the upper bile duct and the confluence of the left and right hepatic duct. The middle and lower bile ducts and gallbladder are almost normal. Ant., anterior; post., posterior; B2, B3, and $B 4$ indicate the segmental ducts of $\mathrm{S} 2, \mathrm{~S} 3$, and $\mathrm{S} 4$, respectively both differentiating benign and malignant biliary strictures and in diagnosing the superficial mucosal spread of cholangiocarcinoma along the bile duct wall. ${ }^{38,39}$ Peroral cholangioscopy (POCS) is useful in differentiating benign and malignant stenotic lesions of the bile duct; ${ }^{40,41}$ however, it is not so feasible for close examination of the hilar bile duct due to its relatively poor operational performance. ${ }^{41}$ Intraductal ultrasonography (IDUS) has advantages in both diagnosing the depth of invasion, including vascular invasion, and the intramural spread of cholangiocarcinoma along the bile duct wall. ${ }^{42,43}$

\section{Positron emission tomography (PET)}

Although there are no definite opinions about the role of PET in the diagnosis of bile duct cancer, there is a report describing its usefulness in making a diagnosis of distant metastasis ${ }^{44}$ (level III). The diagnostic capability of PET/CT is superior to that of CT alone with respect to distant metastatic lesions, but it is similar with respect to primary lesions ${ }^{30}$ (level IV). Although PET/CT shows excellent diagnostic ability in detecting the mass-forming type of tumor, its usefulness in detecting the invasive type is poor ${ }^{45}$ (level IV). There are almost no reports proving the usefulness of PET in differentiating PSC and bile duct cancer ${ }^{46}$ (level III).

CQ 4 What is the second step in the diagnosis of gallbladder cancer?

In gallbladder cancer, the differential diagnosis and the diagnosis of the degree of extension of the cancer are of importance. Endoscopic ultrasonography (EUS) and CT (including MDCT) are recommended for both of these diagnoses (recommendation $B$ ).

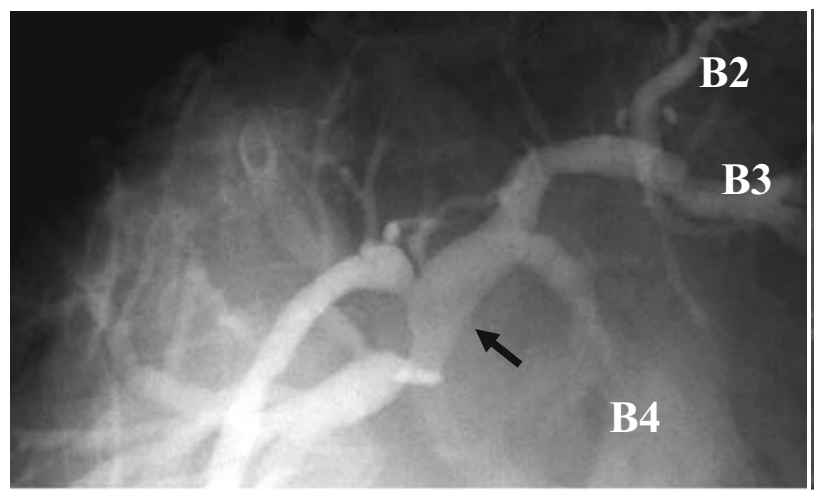

Fig. 8. Percutaneous transhepatic biliary drainage (PTBD) cholangiography for nodular-infiltrating type cholangiocarcinoma. Ductal tapering due to cancer infiltration is seen from the hepatic confluence to the left hepatic duct (arrows). Right

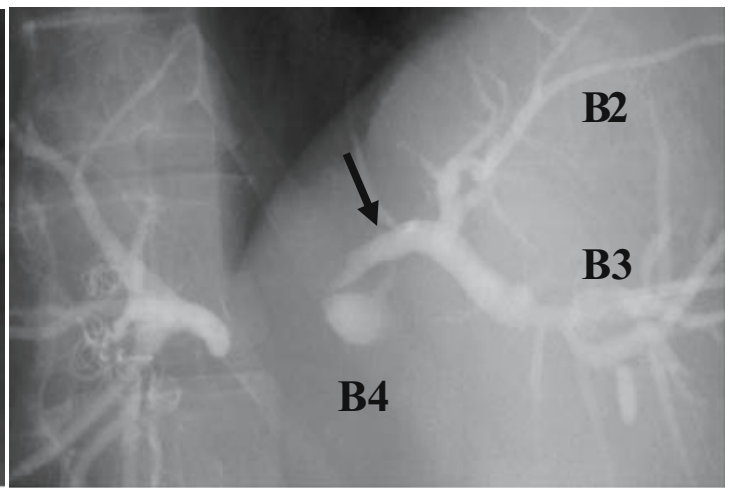

hepatectomy is required for curative resection; however, right trisectionectomy is necessary. $B 2, B 3$, and $B 4$ indicate the segmental ducts of S2, S3, and S4, respectively 


\section{Endoscopic ultrasonography (EUS)}

Endoscopic ultrasonography (EUS) is an excellent procedure for depicting a protruded lesion in the gallbladder and the procedure can be conducted in an outpatient clinic. Its sensitivity in differentiating benign gallbladder disease from gallbladder cancer is reported to be excellent, ranging from $92 \%$ to $97 \%{ }^{47,48}$ (level IV). It is reported that it is also useful for the diagnosis of the depth of mural invasion, the rate of accurate diagnosis being $100 \%$ for invasion limited to the mucosa (m) and muscularis propria (mp), and $75 \%$ for invasion limited to the subserosa (ss) and invasion of the serosal surface (se) or more; also, a diagnosis of the depth of mural invasion was possible in 13 of 14 patients receiving EUS $^{49}$ (level IV). Furthermore, there is also a report that in a case of pedunculated lesions (Ip), according to the classification based on gross appearance, EUS showed that all of these lesions were cancers with invasion limited to the mucosa ${ }^{50}$ (level IV).

\section{$C T$}

There is a report showing that the sensitivity, specificity, and accuracy of CT for a protruded lesion in the gallbladder is $88 \%, 87 \%$, and $87 \%$, respectively, ${ }^{51}$ these values being lower than those of EUS. According to another report, the accuracy of diagnosis of invasion depth by helical CT is $86 \%$ for $\mathrm{T} 1,71 \%$ for $\mathrm{T} 2,81 \%$ for T3, and $95 \%$ for T4 tumors ${ }^{52}$ (level IV). The accuracy of diagnosis of hepatic infiltration was $81 \%$ for cases in which the tumor had infiltrated the hepatic parenchyma less than $2 \mathrm{~cm}$ in length and $100 \%$ for cases with infiltration of more than $2 \mathrm{~cm}^{53}$ (level V).

The rate of detection ${ }^{53}$ of lymph node metastasis with CT is reported to be $38 \%-65 \%{ }^{54,55}$ (level IV). As criteria for decisions on metastasis, Ohtani et al..$^{55}$ indicated that the metastasis should be, in anterior and posterior diameter, larger than $10 \mathrm{~mm}$ and that the images achieved should be ring-like in shape or heterogeneous (level IV).

CT is inferior to EUS in its rate of accurate diagnosis of individual factors in the extension of the lesion. However, CT makes possible the assessment of images of all the surroundings of the lesion, and according to a report on resectability, the accuracy of diagnosis was $93.3 \%{ }^{56}$ (level IV).

\section{$E R C$}

$\mathrm{ERC}$ is useful for assessing the invasion of tumor to the cystic duct and common hepatic duct ${ }^{57,58}$ (level IV). As for the diagnosis of gallbladder cancer with ERC, the positive rate with the use of cytologic diagnosis is reported to be $45 \%-67 \%{ }^{59-62}$ (level IV).

\section{MRI, MRCP}

It is reported that the sensitivity of the diagnosis of hepatic infiltration with MRI is $67 \%-100 \%$ and the specificity is $89 \%$; the sensitivity of invasion to the bile duct is $62 \%-100 \%$ and the specificity is $56 \%-92 \%$; and the sensitivity for lymph node metastasis is $56 \%-92 \%$ and the specificity is $89 \%{ }^{63,64}$ (level IV).

\section{PET}

The assessment of PET or PET/CT in gallbladder cancer is similar to that noted above for the second step in bile duct cancer. ${ }^{30,45}$

CQ 5 What is the second step in the diagnosis of ampullary carcinoma?

Tissue biopsy is conducted for tumor of the papilla (recommendation B). CT and MRI are performed for the diagnosis of distant metastasis and lymph node metastasis (recommendation B). Intraductal ultrasonography (IDUS) and EUS are useful for diagnosis of pancreatic and duodenal invasions (recommendation C1).

The rate of resection of ampullary carcinoma is high and the number of patients in whom this disease is unresectable due to local extension is small (level IV). According to the gross appearance (endoscopic characteristics) of the tumor (Figs. 9, 10), an ulcerative type tumor is often an advanced cancer, ${ }^{65}$ so this type of tumor is not indicated for limited surgery. Therefore, a diagnosis should be made only concerning the suitability of resection. The diagnosis of distant metastasis, including liver metastasis, is now being made by US, CT, and MRI. Recent MDCT techniques ${ }^{66}$ (level IV) enable the production of three-dimensional images, which make clear the anatomical relationship (the presence or absence of invasion ) of a tumor with the bile duct and vessels.

Although ampullary carcinoma presents with symptoms such as jaundice, fever, and abdominal pain, tumor of the papilla is often suspected based on endoscopic and ultrasonographic findings on the occasion of medical examination, which are followed by detailed examination. The second step in the diagnosis of a mass-forming type of tumor is to make a diagnosis of the presence or absence of cancer. Adenoma is indicated for resection because a cancer in adenoma ${ }^{67}$ in which cancer exists in a small region, is not infrequent (level IV). Biopsy is helpful in performing limited surgery for resection or endoscopic resection of the papilla. Many of the tumors for which endoscopic resection of the papilla ${ }^{68}$ has been performed are adenomas. Although there are reports of 


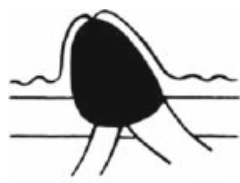

(Non-exposed)

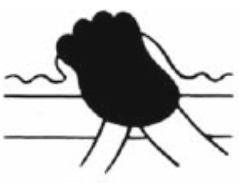

(Exposed)

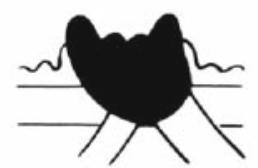

(Predominant protruded type)

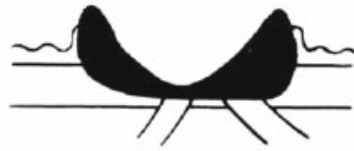

(Predominant ulcerative type)

Protruded type

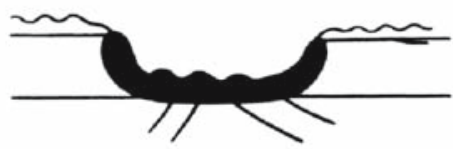

Ulcerative type
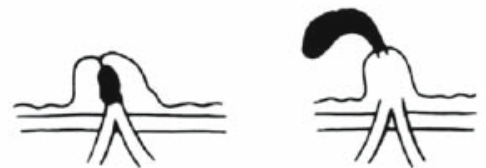

Others
Fig. 9. Macroscopic types of ampullary tumors (with permission from the Japanese Society of Biliary Surgery. Classification of biliary tract carcinoma. Second English edition. Tokyo: Kanehara; 2004.) a
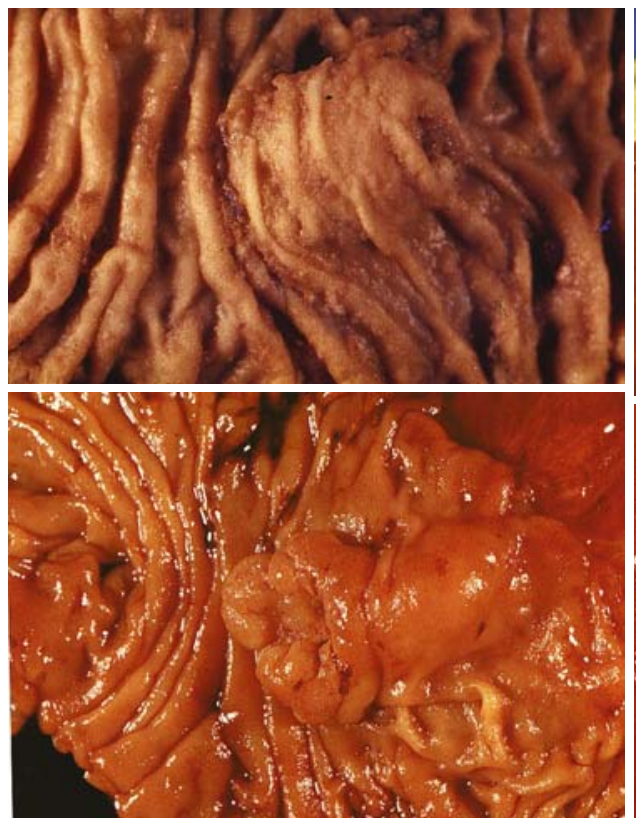

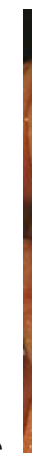

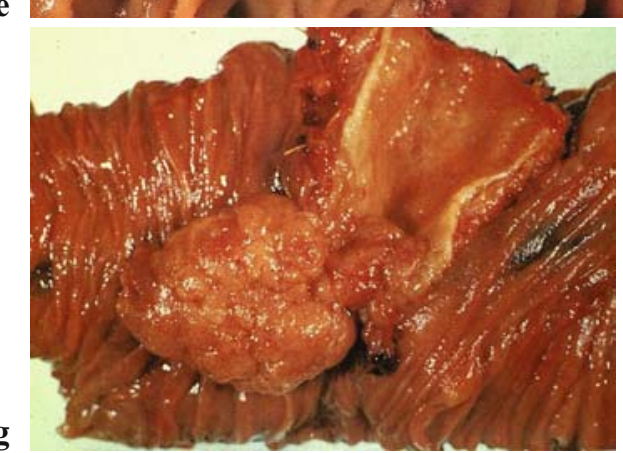

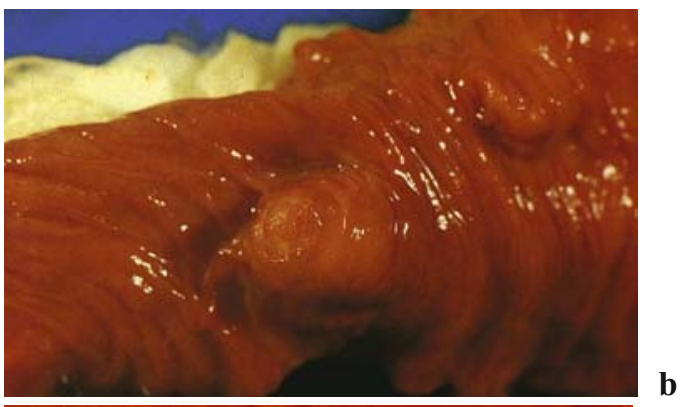
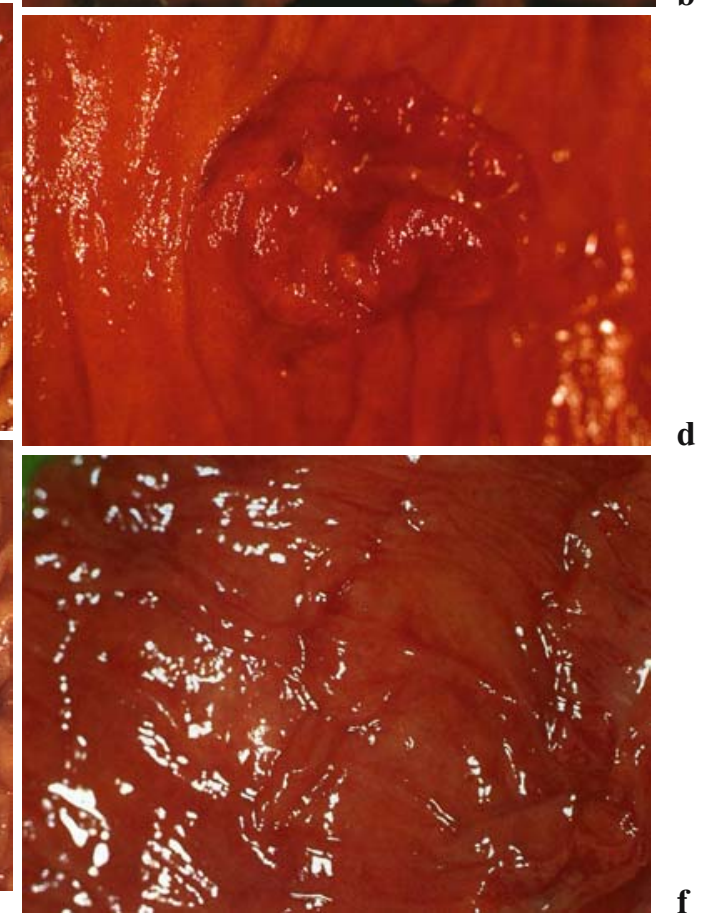

Fig. 10a-g. Gross findings of ampullary carcinomas. a Nonexposed protruded type; b exposed protruded type; c tumor-ulcer type (predominant protruded type); d tumor-ulcer type (predominant ulcerative type); e ulcerative type; f special type (normal-appearing type); g special type (polyp type) (with permission from the Japanese Society of Biliary Surgery. Classification of biliary tract carcinoma. Second English edition. Tokyo: Kanehara; 2004.) 
Table 3. Histopathological findings of primary tumor invasion to the pancreas and the duodenum ${ }^{\mathrm{a}}$

\section{Pancreas}

pPanc0: Invasion limited to Oddi's sphincter or the duodenal wall

pPanc1: Invasion of Oddi's sphincter or the duodenal wall, and/or pancreatic parenchyma

pPancla: Invasion beyond Oddi's sphincter or the duodenal wall, but not to pancreatic parenchyma

pPanc1b: Invasion of the pancreatic parenchyma, which invasion is not more than $5 \mathrm{~mm}$ in depth

pPanc2: Invasion of the pancreatic parenchyma, which invasion is $5 \mathrm{~mm}$ or more but not more than $20 \mathrm{~mm}$ in depth

pPanc3: Invasion of the pancreatic parenchyma, which invasion is $20 \mathrm{~mm}$ or more in depth

\section{Duodenum}

pDu0: Invasion limited to Oddi's sphincter

pDu0 0 : Invasion limited to the duodenal mucosa

pDu0ß: Invasion limited to Oddi's sphincter

pDu1: Invasion beyond Oddi's sphincter, but not to the duodenal muscularis propria

pDu1 $\alpha$ : Invasion limited to the major duodenal papilla

pDu1 $\beta$ : Invasion beyond the major duodenal papilla

pDu2: Invasion of the duodenal muscularis propria

pDu3: Invasion of the duodenal serosa

${ }^{a}$ With permission from the Japanese Society of Biliary Surgery. Classification of biliary tract carcinoma. Second English edition. Tokyo: Kanehara; 2004

cases of cancer in adenoma, they are concerned with discussions of only a small number of cases. A good outcome cannot be achieved for an advanced cancer with the use of limited surgery (level IV).

There are many reports comparing preoperative and postoperative stages with respect to diagnosis of the degree of local extension. It is consistently accepted that depicting tumors by means of US and CT is difficult, but that tumors can be depicted with the use of EUS or IDUS $^{69,70}$ (level II). EUS is an excellent procedure to determine pancreatic invasion, but it is unable to determine histological pancreas invasion pPanc 1a (Table 3). There are also a number of reports demonstrating that determination of histological duodenal invasion $(\mathrm{pDu}$ 1; Table 3) by EUS is also difficult. In the present guidelines, histological determination was made according to the Japanese Society of Biliary Surgery Classification of biliary tract carcinoma. Second English edition (Tokyo: Kanehara; 2004). Although IDUS is superior for making a diagnosis of extension to the pancreas duct or bile duct, pancreatic invasion, and duodenal invasion, the rate of accurate diagnosis being $80 \%-90 \%$, the number of institutions employing EUS and IDUS is small. The use of IDUS has not been taken up widely yet.

Acknowledgment. We would like to express our deep gratitude to the members of the the Japanese Association of Biliary Surgery, the Japanese Society of Hepato-
Biliary-Pancreatic Surgery, and the Japan Society of Clinical Oncology, who provided us with great support and guidance in the preparation of the Guidelines. This process was conducted as part of the Integrated Research Project for Assessing Medical Technology 2005 and 2006 sponsored by the Japanese Ministry of Health, Labour, and Welfare.

We truly appreciate the following active working members who developed the draft of the evidencebased clinical practice Guidelines for the treatment of biliary tract cancer (Japanese version, 2007): Masahiro Kai (Miyazaki), Yasutoshi Kimura (Sapporo), Shigeaki Sawada (Toyama), Hiroaki Shimizu (Chiba), Hisatoshi Nakagawara (Kanazawa), Kohei Nakachi (Kashiwa), and Hiroyuki Yoshitome (Chiba). We also appreciate very much the following members who reviewed and approved the final Japanese version of the guidelines: Hiromitsu Saisyo (Ichikawa), Munemasa Ryu (Chiba), Satoru Shikata (Kyoto), and Yuji Nimura (Nagoya).

\section{References}

1. Takada T, Miyazaki M, Miyakawa S, Tsukada K, Nagino M, Kondo $\mathrm{S}$, et al. Purpose, use, and preparation of clinical practice guidelines for the management of biliary tract and ampullary carcinomas. J Hepatobiliary Pancreat Surg 2008;15:2-6.

2. Yeo CJ, Pitt HA, Cameron JL. Cholangiocarcinoma. Surg Clin N Am 1990;70:1429-47.

3. Thuluvath PJ, Rai R, Venbrux AC, Yeo CJ. Cholangiocarcinoma: a review. Gastroenterologist 1997;5:306-15.

4. Lazaridis KN, Gores GJ. Cholangiocarcinoma. Gastroenterology 2005;128:1655-67.

5. Sugiyama M, Atomi Y, Kuroda A, Muto T. Bile duct carcinoma without jaundice: clues to early diagnosis. Hepatogastroenterology 1997;44:1477-83.

6. Wanebo HJ, Castle WN, Fechner RE. Is carcinoma of the gallbladder a curable lesion? Ann Surg 1982;195:624-31.

7. Malik IA. Clinicopathological features and management of gallbladder cancer in Pakistan: a prospective study of 233 cases. J Gastroenterol Hepatol 2003;18:950-3.

8. Al-Quadah MS, Daradkeh S, Sroujieh AS, Farah GR, Masaad J. Gallbladder carcinoma in Jordan. Hepatogastroenterology 2005; 61:5-7.

9. Trede M. Periampullary and pancreatic cancer. In: Blumgart LH, editor. Surgery of the liver and biliary tract. $2^{\text {nd }}$ ed. New York: Churchill Livingstone; 1994. p. 997-1008.

10. Dijkum EJMN, Terwee CB, Oosterveld P, Meulen JHP, Gouma DJ, Haes JCJM. Validation of the gastrointestinal quality of life index for patients with potentially operable periampullary carcinoma. Br J Surg 2000;87:110-5.

11. Kamisawa $\mathrm{T}, \mathrm{Tu} \mathrm{Y}$, Egawa $\mathrm{N}$, Nakajima $\mathrm{H}$, Horiguchi $\mathrm{S}$, Tsuruta K, Okamoto A. Clinicopathologic features of ampullary carcinoma without jaundice. J Clin Gastroenterol 2006;40:1626.

12. de Groen PC, Gores GJ, LaRusso NF, Gunderson LL, Nagorney DM. Biliary tract cancers. New Engl J Med 1999:341:1368-79.

13. Khan SA, Thomas HC, Davidson BR, Taylor-Robinson SD. Cholangiocarcinoma. Lancet 2005; 366:1303-14.

14. Robledo R, Muro A, Prieto ML. Extrahepatic bile duct carcinoma. US characteristics and accuracy in demonstration of tumors. Radiology 1996;198:869-73. 
15. Choi BL, Lee JH, Han MC, Kim SH, Yi JG, Kim CW. Hilar cholangiocarcinoma: Comparative study with sonography and CT. Radiology 1989;172:689-92.

16. Lillemoe KD. Tumors of the gallbladder, bile duct, and ampulla. Semin Gastrointest Dis 2003;14:208-21.

17. Misra S, Chaturvedi A, Misra NC, Sharma ID. Carcinoma of the gallbladder. Lancet Oncol 2003;4:167-76.

18. Piantino P, Fusaro A, Randone A, Cerchier A, Daziano E. Increased levels of CA19-9, CA50 and CA125 in patients with benign disease of biliary tract and the pancreas. J Nucl Med Allied Sci 1990;34:97-102.

19. Patel AH, Harnois DM, Klee GG, LaRusso NF, Gores GJ. The utility of CA 19-9 in the diagnoses of cholangiocarcinoma in patients without primary sclerosing cholangitis. Am J Gastroenterol 2000;95:204-7.

20. Nichols JC, Gores GJ, LaRusso NF, Wiesner RH, Nagorney DM, Ritts RE. Diagnostic role of serum CA 19-9 for cholangiocarcinoma in patients with primary sclerosing cholangitis. Mayo Clin Proc 1993;68:874-9.

21. Khan SA, Davidson BR, Goldin R, Pereira SP, Rosenberg WM, Taylor-Robinson SD, et al.; British Society of Gastroenterology. Guidelines for the diagnosis and treatment of cholangiocarcinoma: consensus document. Gut 2002;51:1-9.

22. Pasanen PA, Eskelinen M, Partanen K, Pikkarainen P, Penttilä I, Alhava E. Clinical value of serum tumor markers CEA, CA50 and CA242 in the distinction between malignant versus benign diseases causing jaundice and cholestasis: results from a prospective study. Anticancer Res 1992;12:1687-93.

23. Vij U, Baskaran V. Value of serum CEA and AFP in the diagnosis and prognosis of carcinoma gallbladder. Trop Gastroenterol 2001;22:227-9.

24. Chaube A, Tewari M, Singh U, Shukla HS. CA 125: a potential tumor marker for gallbladder cancer. J Surg Oncol 2006;93: $665-9$.

25. Han JK, Choi BI, Kim AY, An SK, Lee JW, Kim TK, Kim SW. Cholangiocarcinoma: pictorial essay of $\mathrm{CT}$ and cholangiographic findings. Radiographics 2002;22:173-87.

26. Chen HW, Pan AZ, Zhen ZJ, Su SY, Wang JH, Yu SC, Lau WY. Preoperative evaluation of resectability of Klatskin tumor with 16-MDCT angiography and cholangiography. AJR Am J Roentgenol 2006;186:1580-6.

27. Campbell WL, Peterson MS, Federle MP, Siqueira ES, Slivka A, Grazioli L, et al. Using CT and cholangiography to diagnose biliary tract carcinoma complicating primary sclerosing cholangitis. AJR Am J Roentgenol 2001;177:1095-100.

28. Johnson KJ, Olliff JF, Olliff SP. The presence and significance of lymphadenopathy detected by CT in primary sclerosing cholangitis. Br J Radiol 1998;71:1279-82.

29. Noji T, Kondo S, Hirano S, Tanaka E, Ambo Y, Kawarada Y, Morikawa T. CT evaluation of paraaortic lymph node metastasis in patients with biliary cancer. J Gastroenterol 2005;40:73943.

30. Petrowsky H, Wildbrett P, Husarik DB, Hany TF, Tam S, Jochum $\mathrm{W}$, Clavien PA. Impact of integrated positron emission tomography and computed tomography on staging and management of gallbladder cancer and cholangiocarcinoma. J Hepatol 2006; 45:43-50.

31. Lopera JE, Soto JA, Munera F. Malignant hilar and perihilar biliary obstruction: use of MR cholangiography to define the extent of biliary ductal involvement and plan percutaneous interventions. Radiology 2001;220:90-6.

32. Romagnuolo J, Bardou M, Rahme E, Joseph L, Reinhold C, Barkun AN. Magnetic resonance cholangiopancreatography: a meta-analysis of test performance in suspected biliary disease. Ann Intern Med 2003;139:547-57.

33. Barish MA, Yocel EK, Ferrucci JT. Magnetic resonance cholangiopancreatography. New Engl J Med 1999;341:258-64.

34. Park MS, Kim TK, Kim KW, Park SW, Lee JK, Kim JS, et al. Differentiation of extrahepatic bile duct cholangiocarcinoma from benign stricture: findings at MRCP versus ERCP. Radiology 2004;233:234-40.

35. Figueras J, Llado L, Valls C, Serrano T, Ramos E, Fabregat J, et al. Changing strategies in diagnosis and management of hilar cholangiocarcinoma. Liver Transpl 2000;6:786-94.

36. Sakamoto E, Nimura Y, Hayakawa N, Kamiya J, Kondo S, Nagino $\mathrm{M}$, et al. The pattern of infiltration at the proximal border of hilar bile duct carcinoma: a histologic analysis of 62 resected cases. Ann Surg 1998;227:405-11.

37. Hayashi S, Miyazaki M, Kondo Y, Nakajima N. Invasive growth patterns of hepatic hilar ductal carcinoma. A histologic analysis of 18 surgical cases. Cancer 1994;73:2922-9.

38. Nimura Y, Kamiya J, Hayakawa N, Shionoya S. Cholangioscopic differentiation of biliary strictures and polyps. Endoscopy 1989;21 Suppl 1:351-6.

39. Nimura Y. Staging of biliary carcinoma: cholangiography and cholangioscopy. Endoscopy 1993;25:76-80.

40. Itoi T, Sofuni A, Itokawa F, Tsuchiya T, Kurihara T, Ishii K, et al. Peroral cholangioscopic diagnosis of biliary-tract diseases by using narrow-band imaging (with videos). Gastrointest Endosc 2007;66:730-6.

41. Fukuda Y, Tsuyuguchi T, Sakai Y, Tsuchiya S, Saisyo H. Diagnostic utility of peroral cholangioscopy for various bile-duct lesions. Gastrointest Endosc 2005;62:374-82.

42. Tamada K, Ido K, Ueno N, Ichiyama M, Tomiyama T, Nishizono $\mathrm{T}$, et al. Assessment of hepatic artery invasion by bile duct cancer using intraductal ultrasonography. Endoscopy 1995;27:57983.

43. Tamada K, Nagai H, Yasuda Y, Tomiyama T, Ohashi A, Wada S, et al. Transpapillary intraductal US prior to biliary drainage in the assessment of longitudinal spread of extrahepatic bile duct carcinoma. Gastrointest Endosc 2001;53:300-7.

44. Kluge R, Schmidt F, Caca K, Barthel H, Hesse S, Georgi P, et al. Positron emission tomography with [(18)F] fluoro-2-deoxy-D glucose for diagnosis and staging of bile duct cancer. Hepatology 2001;33:1029-35.

45. Anderson CD, Rice MH, Pinson CW, Chapman WC, Chari RS, Delbeke D. Fluorodeoxyglucose PET imaging in the evaluation of gallbladder carcinoma and cholangiocarcinoma. J Gastrointest Surg 2004;8:90-7.

46. Cullen SN, Chapman RW. Current management of primary sclerosing cholangitis. Aliment Pharmacol Ther 2005;21:933-48.

47. Sugiyama M, Atomi Y, Yamato T. Endoscopic ultrasonography for differential diagnosis of polypoid gallbladder lesions: analysis in surgical and follow up series. Gut 2000;46:250-4.

48. Azuma T, Yoshikawa T, Araida T, Takasaki K. Differential diagnosis of polypoid lesion of the gallbladder by endoscopic ultrasonography. Am J Surg 2001;181:65-70.

49. Hirooka Y, Naitoh Y, Goto H, Ito A, Hayakawa S, Watanabe Y, et al. Contrast-enhanced endoscopic ultrasonography in gallbladder diseases. Gastrointest Endosc 1998;48:406-10.

50. Sadamoto Y, Kubo H, Harada N, Tanaka M, Eguchi T, Hawata H. Preoperative diagnosis and staging of gallbladder carcinoma by EUS. Gastrointest Endosc 2003;58:536-41.

51. Furukawa H, Kosuge T, Shimada K, Yamamoto J, Kanai Y, Mukai $\mathrm{K}$, et al. Small polypoid lesions of the gallbladder. Arch Surg 1998;133:735-9.

52. Yoshimitsu K, Honda H, Shinozaki K, Aibe H, Kuroiwa T, Irie H, et al. Helical CT of the local spread of carcinoma of the gallbladder: evaluation according to the TNM system in patients who underwent surgical resection. AJR Am J Roentgenol 2002; 179:423-8.

53. Ohtani T, Shirai Y, Tsukada K, Muto T, Hatakeyama K. Spread of gallbladder carcinoma: CT evaluation with pathologic correlation. Abdom Imaging 1996;21:195-201.

54. Engels JT, Balfe DM, Lee JKT. Biliary carcinoma: CT evaluation of extrahepatic spread. Radiology 1989;172:35-40.

55. Ohtani T, Shirai Y, Tsukada K. Carcinoma of the gallbladder: CT evaluation of lymphatic spread. Radiology 1993;189:875-80. 
56. Kumaran V, Gulati S, Paul B, Pande GK, Sahni P, Chattopadhyay TK. The role of dual-phase helical CT in assessing resectability of carcinoma of the gallbladder. Eur Radiol 2002;12:1993-9.

57. Kaneoka Y, Yamaguchi A, Isogai M, Harada T, Suzuki M. Hepatoduodenal ligament invasion by gallbladder carcinoma: histologic pattern and surgical recommendation. World J Surg 2003; 27:260-5.

58. Nakata T, Kobayashi A, Miwa S, Soeda J, Miyagawa S. Impact of tumor spread to the cystic duct on the prognosis of patients with gallbladder carcinoma World J Surg 2007;31:155-61.

59. Rajagopalan V, Daines WP, Grossbard ML, Kozuch P. Gallbladder and biliary tract carcinoma: a comprehesive update, part 1. Oncology 2004;18:889-96.

60. Verma K, Bhargava DK. Cytologic examination as an adjunct to laparoscopy and guided biopsy in the diagnosis of hepatic and gallbladder neoplasia. Acta Cytol 1982;26:311-6.

61. Ishikawa $\mathrm{O}$, Ohhigashi $\mathrm{H}$, Sasaki $\mathrm{Y}$, Imaoka $\mathrm{T}$, Wada A, Ishiguro $\mathrm{S}$, et al. The usefulness of saline irrigated bile for the intraoperative cytologic diagnosis of tumors and tumorlike lesions of the gallbladder. Acta Cytol 1988;32:475-81.

62. Akosa AB, Barker F, Desa L, Benjamin I, Krausz T. Cytologic diagnosis in the management of gallbladder carcinoma. Acta Cytol 1995;39:494-8.

63. Kim JH, Kim TK, Eun HW. Preoperative evaluation of gallbladder carcinoma: efficacy of combined use of MR imaging, MR cholangigraphy, and contrast-enhanced dual phase three dimen- sional MR angiography. J Magn Reson Imaging 2002;16:67684.

64. Schwartz LH, Black J, Fong, Jarnagin W, Blumgart L, Gruen D, et al. Gallbladder carcinoma: findings at MR imaging with MR cholangiopancreatography 2002;26:405-10.

65. Futakawa N, Kimura W, Wada Y, Muto T. Clinicopathological characteristics and surgical procedures for carcinoma of the papilla of Vater. Hepatogastroenterology 1996;43:260-7.

66. Mortele JK, Ji H, Ros PR. CT and magnetic resonance imaging in pancreatic and biliary tract malignancies. Gastrointest Endosc 2002;56:206-12.

67. Yamaguchi K, Enjoji M, Kitamura K. Endoscopic biopsy has limited accuracy in diagnosis of ampullary tumors. Gastrointest Endosc 1990;36:588-92.

68. Bohnacker S, Soehendra N, Maguchi H, Chung JB, Howell DA. Endoscopic resection of benign tumors of the papilla of Vater. Endoscopy 2006;38:521-5.

69. Menzel J, Hoepffner N, Sulkowski U, Reimer P, Heinecke A, Poremba C, Domschke W. Polypoid tumors of the major duodenal papilla: preoperative staging with intraductal US, EUS, and CT-a prospective, histopathologically controlled study. Gastrointest Endosc 1999;49:349-57.

70. Itoh A, Goto H, Naitoh Y, Hirooka Y, Furukawa T, Hayakawa T. Intraductal ultrasonography in diagnosing tumor extension of cancer of the papilla of Vater. Gastrointest Endosc 1997;45: 251-60. 